\title{
THE ATOMIC PHYSICS FACILITY AT THE LBL ECR SOURCE
}

\author{
D. J. Clark, C. M. Lyneis, M. H. Prior and R, G. Stokstad \\ Nuclear Science Division, Lawrence Berkeley Laboratory, 1 Cyclotron Road, \\ Berkeley, California 94720, U.S.A.* \\ S. Chantrenne and P. O. Egan \\ Lawrence Livermore National Laboratory, P.O. Box 808, L-296, Livermore, \\ California 94550, U.S.A.**
}

\section{DISCLAIMER}

\begin{abstract}
This report was prepared as an account of work sponsored by an afency of the United States Government. Neither the United States Government nor any agency thercol, nor any of their emplayees, makes any warranty, express or implied, or assumes any legal liability or responsibility for the accuracy, completeness, or usefulness of any information, apparatus, product, or process disclosed, or represents that its use would not infringe privately owned rights. Reference herein to any specific commercial product, process, or service by trade name, tsademark, manufacturer, or otherwise does not necessarily constitute or imply its endorsement, rccommendation, or favoring by the United States Guvernment or any agency thereof. The views and opinions of authors expressed herein do not necessarily state or reflect those of the United States Government or any agency thereof.
\end{abstract}

*This work was supported by the Director, Office of Energy Research, Division of Nuclear Physics of the Office of High Energy and Nuclear Physics of the U.S. Department of Energy under Contract DE- ACO3-76SF00098.

**This work was performed under the auspices of the U.S. Deparment of Energy by Lawrence Livermore National Labor::ory under Contract W-7405-Eng-48. 
THE ATOMIC PHYSICS FACILITY AT THE LBL ECR SOURCE

\author{
D. J. Clark, C. M. Lyneis, M. H. Prior and R. G. Stokstad \\ Nuclear Science Division, Lawrence Berkeley Laboratory, 1 Cyclotron Road, \\ Berkeley, California 94720, U.S.A. \\ S. Chantrenne and P. O. Egan \\ Lawrence Livermore National Laboratory, P.O. Box 808, L-296, Livermore, \\ California 94550, U.S.A.
}

\begin{abstract}
A low energy beam line facility for atomic and surface physics research has been added to the injection line of the ECR source at the LBL 88-Inch Cyclotron. Beams throughout the periodic table can be delivered to 3 beam line stations at energies up to $15 \mathrm{Q} \mathrm{keV}$. Experiments using this facility include forbidden line emission from the ion beam, ion-atom collisions, merged electron-ion beams and sputtering by highly charged ions.
\end{abstract}

\title{
1. The ECR Source
}

The LBL ECR Source (l) is used primarily to axially inject a wide range of positive ion beams into the LBL sector-focused 88-Inch Cyclotron. Cyclotron beams of mass number $1-150$ have been accelerated to $5 \mathrm{MeV} / \mathrm{u}$ for the heaviest jons, and up to 32 $\mathrm{MeV} / \mathrm{u}$ for the lighter ions surh as ${ }^{4} \mathrm{He}$ and $16 \mathrm{O}$. Experiments with these beams include heavy ion reactions, nuclear structure and radiation damage studies of electronic circuits. During periods when the cyclotron is not scheduled for these experiments, the ECR source is available for development studies and for atomic and surface physics research, using the beam directly from the source.

The source is shown in Fig. 1. It is a 2 stage source with independent microwave feeds for each stage. The first stage provides a low charge state plasma for the second stage, where the high charge states are created in a stepwise ionization process by electrons up to $100 \mathrm{keV}$ in energy. The confining magnetic tield is supplied by circular coils and a permanent magnet sextupole. The second stage coils form a mirror field of about $3 \mathrm{kG}$, where electrons are trapped and accelerated by cyclotron resonance 
heating. Microwave power is typically $150 \mathrm{~W}$ at $8.6 \mathrm{GHz}$ for the first stage and $400 \mathrm{~W}$ at $6.4 \mathrm{GHz}$ for the second stage. Beam is extracted by an accel-decel puller. The source is biased at +5 to $15 \mathrm{kV}$, giving beam energies of $5-15 \mathrm{Q} \mathrm{keV}$. The source is pumped by 3 baffled diffusion pumps.

Beam from the source is focused by a Glaser (solenoid) lens to $X-Y$ defining slits, as shown in Fig. 3. A 90 degree analyzing magnet separates the charge states at the next X-Y slits. At the full transmission width of these slits, adjacent isotopes up to mass 60 can be separated, and at half this width adjacent isotopes up to mass 130 (xenon) can be separated. The current available in one charge state is measured with a Faraday cup behind these analyzing slits. The currents available from this source are summarized in references (1) and (2). A surimary contour graph of the charge states available for several current levels, without collimation, for elements up to atomic number 83, is shown in Fig. 2. Typical curents are $60 \mathrm{e}_{\mathrm{A}} \mathrm{O}^{6+}, .5 \mathrm{e} \mu \mathrm{A} \mathrm{O} \mathrm{O}^{8+}, 10$ $\mathrm{c} \mu \mathrm{A} \mathrm{Ar}^{12+}, 8 \mathrm{e} \mu \mathrm{A} \mathrm{Ca}^{12+}$ and $5 \mathrm{e} \mu \mathrm{A} \mathrm{Kr}^{16+}$. Easiest tuning is done with gas feed, but the use of low and high temperature ovens makes solid feed about as efficient as gas feed (2). A beam attenuator just before the 90 degree magnet (Fig. 3) contains an attenuator box with 6 meshes on air cylinder drives, which can give beam attenuation factors ranging from 2 up to $10^{9}$ in a few seconds (3). The vacuum system uses cryopumps and turbo-pumps, with conflat type metal seais for the various feed-thru flanges, to maintain a vacuum of less than $10^{-7}$ torr.

\section{The Atomic Physics Facility}

When the source is not scheduled for cyclotron runs or development, its charge analyzed beams can run in the atomic physics facility, shown on the right side of Fig. 3. The source and the facility are located on top of the cyciotron vault roof. They can be used when the cyclotron is run on other ion sources because of the radiation shielding provided by the concrete roof blocks. The beam is switched from the cyclotron injection line to the atomic physics facility by a 70 degree magnet just after the analyzing slits. A 40 degree magnet is used to switch the beam to one of the atomic or surface physics experiments. Focusing is provided by magnet edges and by einzel lenses. Einzel lenses, rather than quadrupoles or solenoids, were chosen for focusing because they are simple and cheap. Fig. 3 does not show all the focusing lenses in the center and right lines coming from the 40 degree magnet. Furaday cups, beam scanners and slits in the lines provide diagnostics and beam collimation. Pumping is by turbo 
and cryopumps, and metal seals are used on flanges. The tuning of the beam to the target has proven to be straightforward, using the collimators for centering, and lenses for peaking on target.

First order beam optics calculations were made to optimize the transport through the bending magnets to the experiments. An estimate of the reduction of magnet vertical edge focusing due to the fringing field was included. The einzel lenses were simulated by magnet edges which focus in both planes. A sample beam profile is shown in Fig. 4 for beam transport from the source region to the experiment on the left line of the 40 degree magnet. The figure shows the half width of the beam phase space ellipse in the $X$ (horizontal) and $Y$ (vertical) planes. The assumed emittance is $190 \pi \mathrm{mm}$ mrad, un-normalized, in both planes. This contains most of the beam current (4). The calculation starts at the first $X-Y$ defining slit after the source, with a beam width equal to the normal slit width. The 90 degree magnet is approximately double focusing and focuses the beam into a radial waist at the $X-Y$ analyzing slit where the charge states are separated. The 70 degree magnet is located just after this waist to minimize the magnet aperture requirement. The horizontal and vertical focusing of the 70 degree magnet produce a lower divergence beam which is easier to transport. The einzel lens focuses this beam into the gap of the 40 degree magnet, again minimizing the aperture. A final einzel lens focuses the beam in to the first aperture of the atomic physics experiment.

\section{Atomic and Surface Physies Experiments}

The program of atomic physics utilizing this facility covers a variety of collision studies, including the study of multiple electron transfer in ion-atom collisions (5), and quasi-molecular $\mathrm{X}$-ray emission from $\mathrm{H}$-like $\mathrm{Ne}^{9+}$ collisions with $\mathrm{Ne}$ atoms (6). In another experiment, shown on the right line of the 40 degree magnet in Fig. 3, Auger electron spectroscopic studies are made of multiply excited states formed in highly chirged projectiles by electron capture from atomic targets (7). These Auger studies are aimed at understanding the capture mechanisms, and produce new energy level measurements and production cross-sections. Studies of forlidden photon emission lines, in the visible range, from metastable ion 'oeam components has been carried out for a number of highly charged ions with incomplete $2 \mathrm{p}$ or $3 \mathrm{~d}$ subshells (e.g. $\mathrm{Ar}^{9+}$, $\mathrm{Nb}^{15+}$ ) (8). This work provides improved values for fine structure intervals, previously known only indirectly from measurement of shon wavelength (XUV or soft $\mathrm{X}$-ray) allowed transitions. Currently most of these experiments are continuing, and 
are described in more detail in (9). In addition a novel merged electron-ion beam apparatus is under test to provide electron excitation cross-sections from ion targets. The beams are merged with a trochoidal analyzer. The final electron beam is then analyzed with a second trochoidai analyzer and a position sensitive detector. This experiment, the energy loss spectrometer, is shown on the left line of the 40 degree magnet in Fig. 3.

In the surface physics experiments a series of studies have been made of sputtering yields and angular distributions for multiply charged Ar ions impacting at normal incidence upon surfaces of metal and crystal targets. One goal of this work was to study the sputtering process in a regime where the potential energy brought to the surface by a highly charged ion is comparable to the kinetic energy. Examples of ion-surface combinations are $\mathrm{Ar}^{4+}-11+$ at $48 \mathrm{keV}$ onto $\mathrm{LiNbO}_{3}, \mathrm{CsI}, \mathrm{LiTaO}_{3}, \mathrm{NaCl}$ and Au. Both Rutherford back scattering analysis of collected material and on line detection of atomic emission lines ( $\mathrm{Na}$ from $\mathrm{NaCl}$ ) have been used to monitor the sputtering process.

\section{References}

(1) C. M. Lyneis, Proc. Int'l Conf. on ECR Ion Sources and their Applications, East Lansing, MI, ed. J. Parker, NSCL Rept. \#MSUCP-47 (1987) 42.

(2) D. J. Claik and C. M. Lyneis, The Production of Beams from Solid Materials at the LBL ECR Source, Int'l Confi. on the Physics of Multiply Charged lons and Workshop on E.C.R. Ion Sources, Grenoble (1988) (to be published).

(3) R. F. Burton, D. J. Clar!: and C. M. Lyneis, Nucl. Instr. \& Meth. in Phys. Res. A270 (1988) 198.

(4) D. J. Clark, Proc. Int'l Conf. on ECR Ion Sources and their Applications, East Lansing, MI, ed. J. Parker, NSCL Rept. \#MSUCP-47 (1987) 433.

(5) H. Schmidt-Boecking, M. H. Prior, R. Doerner, H. Berg, J. O. K. Pedersen, C. L. Cocke, M. Stockli and A. S. Schlachter, Phys. Rev. A37 (1988) 4640.

(6) H. Schmidt-Boecking, M. H. Prior, J. O. K. Pedersen, C. L. Cocke, R. Doerner and H. Berg, Bull. Am. Phys. Soc. 33 (1988) 920.

(7) D. Schneider, Ar and Fe L-Auger Electron Production in $10 \mathrm{keV} / \mathrm{q} \mathrm{Arq}+(\mathrm{q}=7-10)$ and $\mathrm{Fe}^{17+}$ Collisions with He. (this Conference).

(8) M. H. Prior, J. Optical Soc. Amer. B 4 (1987) 144.

(9) M. H. Prior, Collision and Spectroscopic Studies with Highly Charged lons from the LBL ECR Ion Source. (this Conference). 


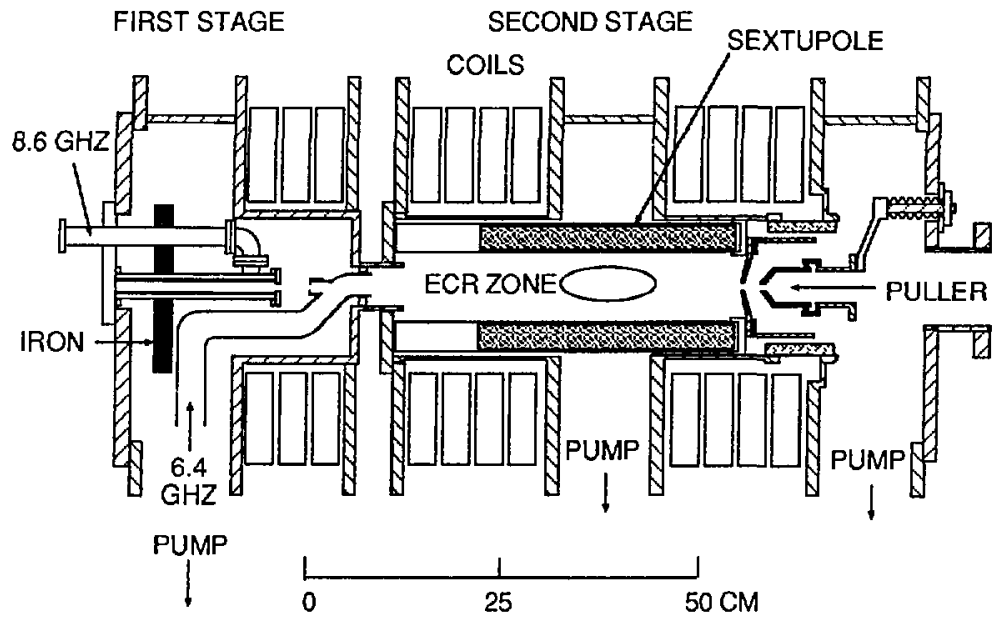

Fig. 1. An elevation cross-section view of the LBL ECR source. 


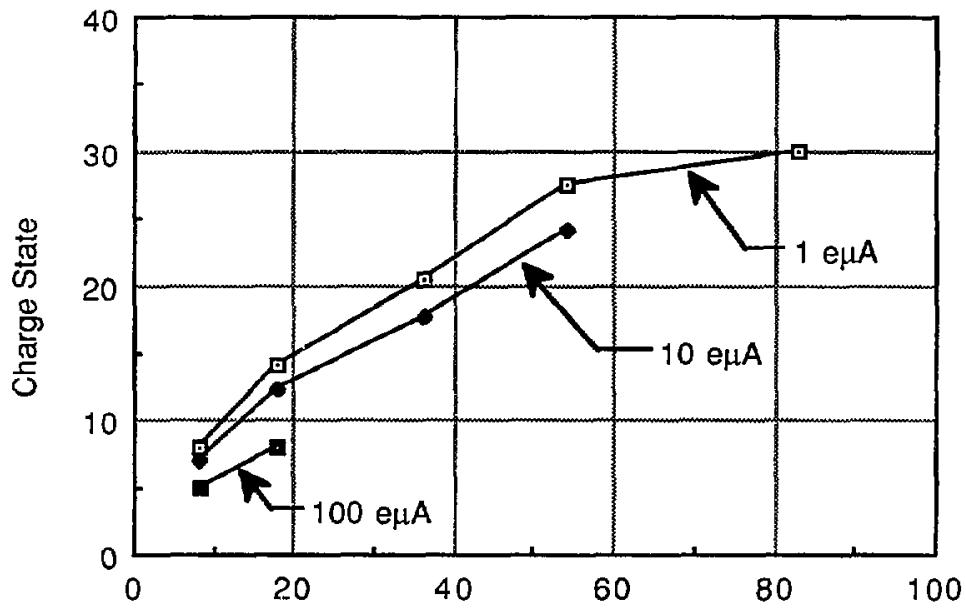

Atomic Number

Fig. 2. Ion charge states available at the $1 \mathrm{e} \mu \mathrm{A}, 10 \mathrm{e} \mu \mathrm{A}$ and $100 \mathrm{e} \mu \mathrm{A}$ levels for the $\mathrm{LBL}$ ECR source. 


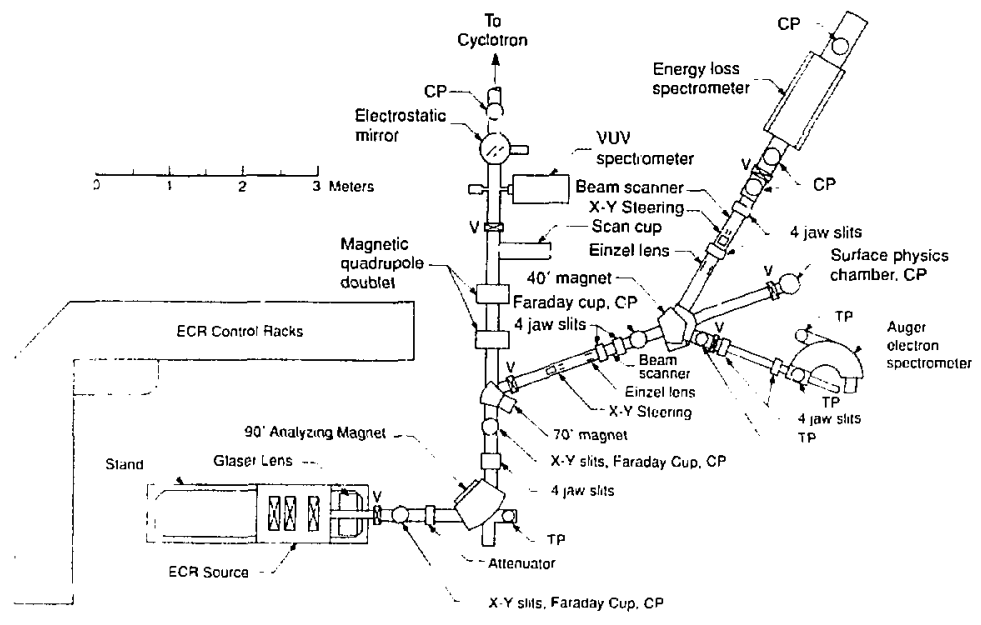

Fig. 3. Layout of the cyclotron vault roof showing the ECR source and atomic physics facility. $\mathrm{V}=$ valve, $\mathrm{TP}=$ turbo-pump, $\mathrm{CP}=$ cryopump. XBL 889-10453. 


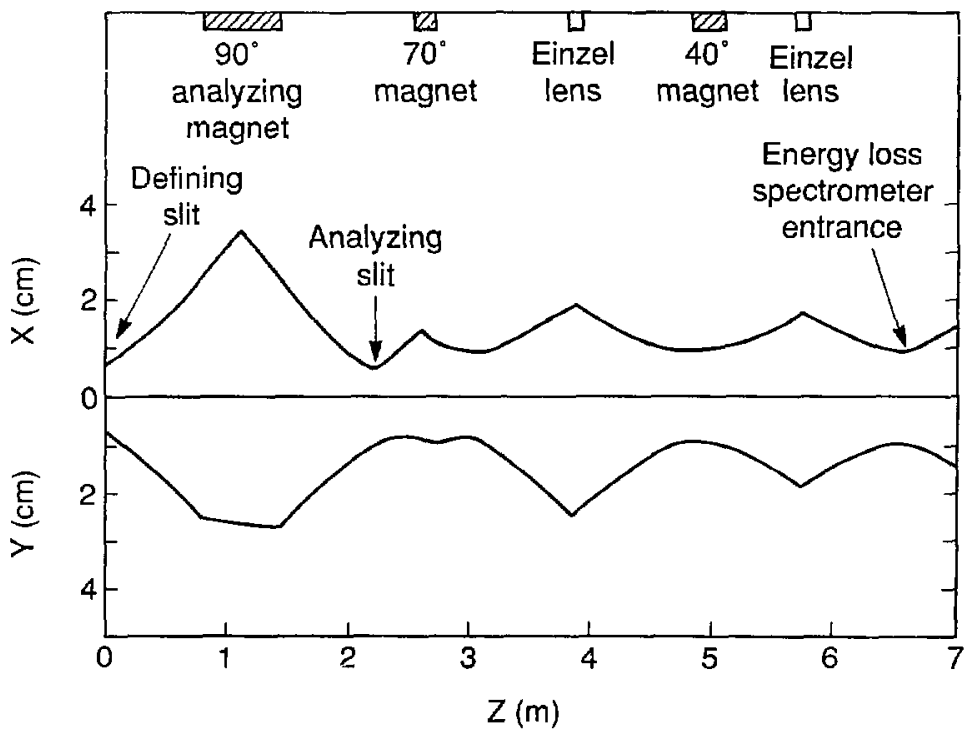

Fig. 4. Beam optics calculation from the ECR source to an atomic physics experiment showing beam profiles. XBL 889-10451. 